\title{
Regulation of Active Oxygen Species in Cu-MnOx through MOFs Templates for Soot Removal
}

Zihan Li ${ }^{a, c}$, Panpan Liu ${ }^{b, c}$, Changsen Zhang ${ }^{b, c, *}$

${ }^{a}$ College of Chemistry, Zhengzhou University, Zhengzhou 450001, Henan, China

${ }^{b}$ School of Ecology and Environment, Zhengzhou University, Zhengzhou 450001,

Henan, China

${ }^{c}$ Environmental Chemistry \& Low Carbon Technologies Key Lab of Henan Province,

Zhengzhou 450001, Henan, China

*Corresponding author.E-mail: zhangcs@zzu.edu.cn. 


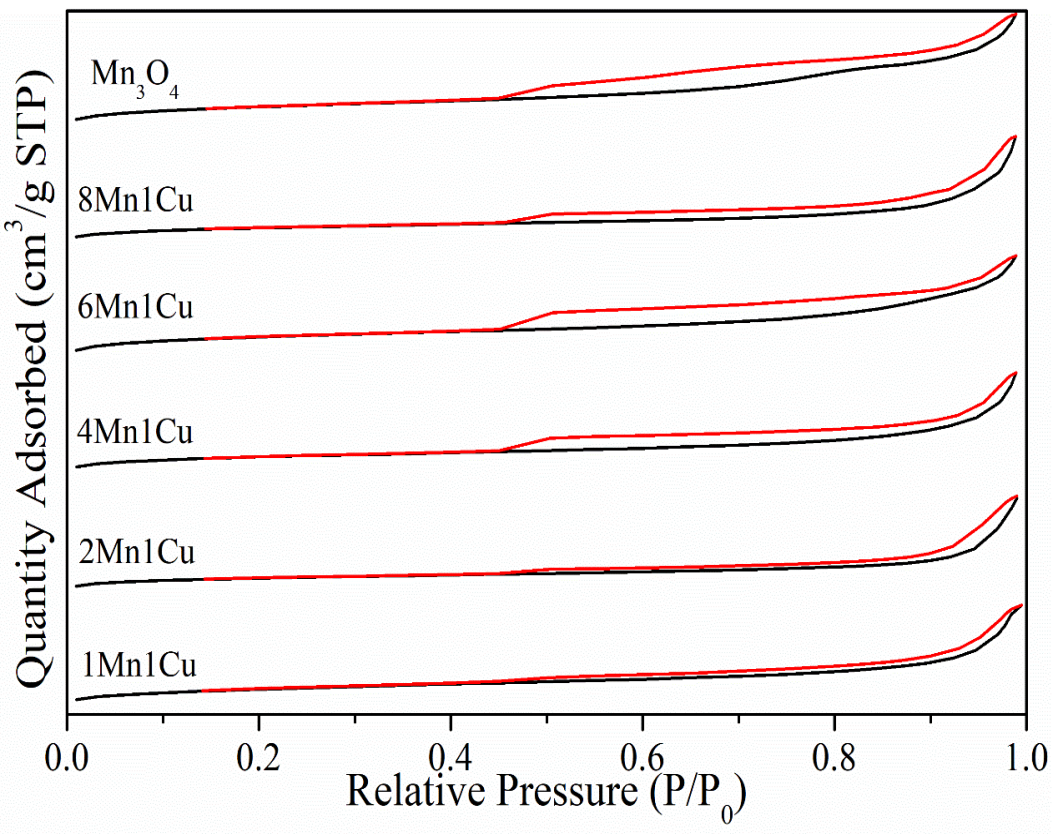

Fig. S1. The $\mathrm{N}_{2}$ physisorption isotherm of $\mathrm{Mn}_{3} \mathrm{O}_{4}$ and $\mathrm{Mn}-\mathrm{CuO}_{\mathrm{x}}$ sample. 